\title{
Characterization of Northern pintail (Anas acuta) ejaculate and the effect of sperm preservation on fertility
}

\author{
L. M. Penfold, V. Harnal, W. Lynch, D. Bird, S. R. Derrickson \\ and D. E. Wildt \\ Conservation and Research Center, National Zoological Park, Smithsonian Institution, \\ Front Royal, VA 22630, USA
}

\begin{abstract}
Northern pintail duck semen and sperm traits were characterized, and the fertility of cold-stored spermatozoa was investigated using artificial insemination. Excellent quality ejaculates containing high proportions of motile spermatozoa were collected from drakes within $20 \mathrm{~s}$ by a massage technique. Semen was collected in Beltsville poultry semen extender, pooled and cold-stored $\left(4^{\circ} \mathrm{C}\right)$ for $0,24,48$ or $72 \mathrm{~h}$. Hens were inseminated with $100 \mu$ twice a week, and eggs were assessed for fertilization and hatch success. Fertilization success was similar $(P>0.05)$ for semen coldstored for $0(51.6 \%), 24(51.5 \%), 48(41.1 \%)$ and $72 \mathrm{~h}$ (22.3\%; $P>0.05)$. Similar $(P>0.05)$ percentages of fertilized eggs hatched to live offspring $(73.1,71.4,87.0$ and
\end{abstract}

$80.0 \%$, respectively). Fresh semen was also equilibrated with 1 or $4 \%$ dimethylsulphoxide or glycerol, and cryopreserved at the following rates: (1) approximately $60^{\circ} \mathrm{C} \mathrm{min}^{-1}$

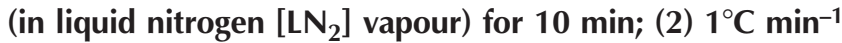
to $-20^{\circ} \mathrm{C}, \mathrm{LN}_{2}$ vapour for $10 \mathrm{~min}$; and (3) $1^{\circ} \mathrm{C} \mathrm{min}^{-1}$ to $-35^{\circ} \mathrm{C}$, all followed by immersion in $\mathrm{LN}_{2}$. After thawing for $30 \mathrm{~s}$ at $37^{\circ} \mathrm{C}$ or $20 \mathrm{~min}$ at $4^{\circ} \mathrm{C}$, sperm motility and viability were assessed. The highest numbers of motile spermatozoa were recovered after slow-fast freezing (2) and thawing at $0^{\circ} \mathrm{C}(P<0.05)$, but survival was inadequate to allow artificial insemination. Nonetheless, cold storage provides an effective means of short-term storage with no loss of fertility in this waterfowl species.

\section{Introduction}

Despite an abundance of waterfowl worldwide (154 species are currently recognized; Ellis-Joseph et al., 1992), the survival of many individual species is threatened. According to a Conservation and Assessment Management Plan Workshop for waterfowl (Ellis-Joseph et al., 1992), species under threat of extinction include the Hawaiian goose or Nene (Branta sandvicensis), Hawaiian duck (Anas wyvlliana), Laysan teal (Anas laysanensis), Tule goose (Anser albifrons gambelli) and Trumpeter swan (Olor buccinator). Other species, like the Northern pintail (Anas acuta) are subject to non-cyclical population decreases or local-regional range contractions, indicative of species or populations that are not yet endangered, but may become so in the near future (US Fish and Wildlife Service, 1999).

As populations decrease in size (in nature or captivity), inbreeding can occur which, in turn, can reduce reproductive fitness (Nei et al., 1975), including fecundity and survivability (Ralls and Ballou, 1986). When genetic variation is maintained or increased, population vigour and the ability to adapt to environmental change are enhanced. Challenges in waterfowl management include crossspecies hybridization (Ankney et al., 1986) that can result in a loss of species uniqueness and specialized adaptive and fitness traits, and failure to reproduce in captivity

Email: Lindap@wogilman.com owing to behavioural problems associated with confinement (Hediger, 1965). One solution to these management challenges is the use of assisted breeding techniques including sperm preservation combined with artificial insemination (AI). Such strategies can complement captive breeding programs by: (1) preserving valuable genes from individuals for infusing into future generations; (2) reducing disease transfer risk by transporting genetic material instead of birds between flocks; and (3) providing a repository of genetic material for species not yet endangered that may be threatened eventually by unexpected hybridization (with common species) or by natural catastrophe. Although information is available on basic sperm physiology from agriculturally valuable birds, especially chickens and turkeys (Bakst, 1990), there is a dearth of information on non-domestic birds. If $\mathrm{Al}$ is to be an effective tool for the management and conservation of rare waterfowl species, a high priority should be basic reproductive studies that focus on consistent sperm collection and sperm sensitivity to cooling and freeze-thawing.

Short-term $(6 \mathrm{~h})$ preservation of semen has been used extensively in the turkey industry (Sexton, 1981; Bakst, 1990), but has been shown to result in reduced fertility over time (Wishart, 1984; Sexton, 1988a; Thurston, 1995). Several studies have addressed the issue of developing cryopreservation techniques for domestic birds, including domestic fowls (Polge, 1951) and domestic drakes (Tai et al., 1983; Tselutin et al., 1995; Watanabe et al., 1981). 
However, few studies have been carried out on nondomestic species (Sexton and Gee, 1978; Gee, 1983) and fewer still for non-domestic waterfowl (Aleutian Canada goose (Branta canadensis); Gee and Sexton, 1990).

The Northern pintail (Anas acuta), a common North American dabbling duck, was used in the present study as a research model for non-domestic waterfowl. This paper describes semen collection efficiency and characterizes sperm traits in a typical Northern pintail ejaculate. Semen handling techniques and the effects of cold storage (shortterm preservation) and cryopreservation (long-term preservation) on duck sperm motility and viability were also investigated. Finally, the effect of short-term sperm preservation on fertility after Al was examined.

\section{Materials and Methods}

\section{Animals}

Bachelor groups of adult Northern pintails (five groups of 9-10 each, total of 46 birds; $2-6$ years, approximately $850 \mathrm{~g}$ each) were housed in outside pens $(20 \mathrm{~m} \times 70 \mathrm{~m})$, each containing a pond. Six groups of four adult, female conspecifics ( $n=26 ; 2-6$ years, approximately $850 \mathrm{~g}$ each) were housed in pens adjacent to males, separated by a chain link fence allowing all birds visual and vocal cue exchange. Individuals in each group were fitted with numbered leg bands for individual identification. Four breeding pairs of Northern pintails were maintained as natural mating controls in similar pens and environmental conditions. All birds were provided with Sinking Duck Diet (Zeigler Bros. Inc., PO Box 95, Gardners, PA) ad libitum, but this was removed from the pens containing the males approximately $12 \mathrm{~h}$ before semen collection. Project approval was granted by the Conservation and Research Centre's Institutional Animal Care and Use Committee.

\section{Nesting and egg laying observations}

Pens contained adequate cover for nest building, including long grass, tufts of pampas grass and small bushes. Females were observed daily for nest building activity, and the resulting nests were checked daily for eggs. After discovery of the first egg, each consecutive egg (laid daily) was numbered with a waterproof marker pen. The number of eggs present in the nest before Al began was noted to ensure that only eggs produced after Al would be considered in the fertility assessments. Nests in control (natural mating) pens were similarly checked, and eggs were numbered. Clutches were designated complete when no new eggs were found after 2 consecutive non-laying days.

\section{Ejaculate collection and processing}

Semen was collected from each bird during April-June, approximately twice a week, for two seasons. Males were caught using a long-handled net and retrained in a supine position. Semen was collected by massaging the ventral aspect of the abdomen towards the cloaca (Gee, 1983). Further massage at the cloacal base caused semen to pool at the cloacal opening. Eversion of the copulatory organ, which could have caused loss of semen over the surface, was avoided. In general, an ejaculate was obtained within 20 s of massage onset, and non-responsive birds were released within $1 \mathrm{~min}$ to prevent handling stress. A tom-cat catheter (Sherwood Medical, St Louis, MO) trimmed to $4 \mathrm{~cm}$ in length and attached to a $1 \mathrm{ml}$ tuberculin syringe was used to aspirate semen from each bird. According to individual experiments (described below), semen was collected neat or immediately placed into Beltsville poultry sexton extender (BPSE; Sexton, 1977) with the osmolarity adjusted to $280 \mathrm{mOsm}$. All samples were transported within $30 \mathrm{~min}$ to the laboratory at ambient $\left(24^{\circ} \mathrm{C}\right)$ or cool $\left(4^{\circ} \mathrm{C}\right)$ temperature (on ice) after placing the catheter in a glass tube in a Styrofoam container.

\section{Semen and sperm assessments}

Semen and sperm analyses were carried out initially on mid-season ejaculates from different drakes. Semen volume was determined by aspiration into a calibrated, positive displacement Eppendorf pipette (Brinkman Instruments Inc., Westbury, NY). Indicator strips (ColorpHast, EM Science, Gibbstown, NJ; $\mathrm{pH}$ range, 6.5-10.0) were used to determine the $\mathrm{pH}$ of neat semen, and osmolarity was determined with a vapour pressure osmometer (Westcor Inc, Logan, UT). Sperm concentration was assessed by diluting neat semen 1:800 with $0.3 \%$ glutaraldehyde in PBS and counting the number of spermatozoa in a $10 \mu \mathrm{l}$ volume using a haemocytometer. The percentage sperm motility and progressive motility (on a scale of $0-5 ; 0=$ non-motile, 5 = highly motile; Howard et al., 1991) were assessed subjectively by diluting neat semen 1:100 and extended semen 1:10 with BPSE (final concentration approximately 1:100). Semen dilution with BPSE enhanced the ability to estimate motility accurately in the normally densely concentrated ejaculate (Mann, 1964). Aliquots $(5 \mu \mathrm{l})$ were placed on a pre-warmed $\left(38^{\circ} \mathrm{C}\right)$ microscope slide, covered with a cover slip $(22 \times 22 \mathrm{~mm})$ and examined under a Leitz Diaplan microscope $(\times 20$; Leica, 6330 Wetzlar). The mean motility of three fields was estimated for each slide. Sperm morphology was assessed by incubating $2 \mu \mathrm{l}$ of neat or extended semen (depending on the study) in $20 \mu \mathrm{l}$ of eosin-nigrosin solution (Burrows and Quinn, 1939) for 2 min. Smears were made on microscope slides, air-dried, and 100 spermatozoa were assessed $(\times 40)$ for the type and proportions of abnormal spermatozoa (pleiomorphisms). Viability, defined as spermatozoa with an intact plasma membrane, was assessed by incubating $200 \mu \mathrm{l}$ semen diluted 2:1 with BPSE with Live-Dead stain consisting of two components, A and B (Molecular Probes, Inc., Eugene, OR; Garner et al., 1994; Kasai et al., 1996). A working solution of component A was made by adding $5 \mu \mathrm{l}$ stock solution (SYBR-14) to $95 \mu$ BPSE (working solution). Diluted semen $(200 \mu \mathrm{l})$ was incubated for 10 min with $2 \mu \mathrm{l}$ 
component A working solution and $2 \mu \mathrm{l}$ stock component B (propidium iodide). Spermatozoa that stained green were considered viable, whereas those that stained red or partially red were assessed as nonviable (Garner et al., 1994; Kasai et al., 1996).

\section{Artificial insemination of females}

Inseminations began after each female had laid the first egg. Each hen was monitored daily for onset of egg production, which opened the reproductive tract and facilitated insertion of the insemination catheter. Each female was captured using a long-handled net and manually restrained. The abdomen was gently palpated to ensure the absence of a shell-covered egg in the oviduct that could prevent semen from reaching the next unfertilized (unshelled) egg. Care was taken during capture, restraint and palpation to avoid breaking a hard-shelled egg within the tract. Extended semen was placed intracloacally using a turkey insemination straw (IMV International Corp., Shingle Creek Parkway, MN) attached to a $1 \mathrm{ml}$ tuberculin syringe (A. Daigger and Company, Heathrow Drive, IL) with a short length of plastic tubing (A. Daigger and Company). Inseminations (100 or $200 \mu \mathrm{l}$ ) containing an average of 3.7-7.4 $\times 10^{9}$ spermatozoa, of which approximately $90 \%$ were motile, see below) were performed twice a week (every 3-4 days) until the clutch was complete. Hens were allowed to incubate complete clutches for 5-7 days, and then eggs were removed, candled to determine fertilization (assessed by observing a small, dark patch surrounded by blood vessels inside the egg) and transferred to an artificial incubator. Approximately 2-3 days before hatching (total incubation time, 21-22 days), eggs were transferred to a surrogate hen and allowed to hatch. Fertilization success was defined as the percentage of eggs produced after $\mathrm{Al}$ commenced that were candled and seen to be fertilized. Hatch success was determined as the number of live ducklings produced from the total number of eggs produced after Al commenced.

\section{Experiment 1: semen characteristics and sperm motility} after ejaculate collection with and without BPSE at $24^{\circ} \mathrm{C}$ or at $4^{\circ} \mathrm{C}$

Ejaculates were collected from 20 individual drakes, transported to the laboratory and assessed for percentage motility, progressive motility and percentage normal sperm morphology.

Semen was collected from three groups of eight randomly selected drakes, four times a week over 5 weeks, and each group was pooled to examine the effects of collection and transport to the laboratory on sperm quality. Pooled ejaculates were assigned randomly to the following treatments: 'neat', extended in $100 \mu \mathrm{l}$ BPSE at ambient temperature $\left(24^{\circ} \mathrm{C}\right)$ or extended in $100 \mu \mathrm{l}$ BPSE and placed in a Styrofoam box on ice $\left(4^{\circ} \mathrm{C}\right)$. After transport to the laboratory (which took approximately $40 \mathrm{~min}$ ) using the three approaches, spermatozoa were immediately assessed for percentage motility, progressive motility and percentage normal sperm morphology.

Experiment 2: fertility and hatchability of eggs after artificial insemination with extended semen versus natural mating

After the results of Expt 1, semen was collected from randomly selected drakes $(n=6-8)$ into tom-cat catheters pre-loaded with $100 \mu \mathrm{l}$ BPSE at ambient temperature and immediately transferred to a glass tube on ice in a Styrofoam container. Individual ejaculates were pooled and assessed for per cent sperm motility, progressive motility, sperm concentration and viability. Hens were inseminated twice a week with 100 or $200 \mu$ l of freshly collected, cooled $\left(4^{\circ} \mathrm{C}\right)$, extended semen. Nests were monitored daily for egg production, and fertility and hatchability were determined and compared with naturally mated controls.

Experiment 3: fertility and hatchability of eggs after artificial insemination with $100 \mu$ l of extended coldstored semen

After the results of Expt 2, semen was collected from randomly selected drakes into tom-cat catheters preloaded with $300 \mu$ I BPSE to ensure sufficient extension for subsequent assessments and inseminations. Individual ejaculates were pooled $(n=6)$ and assessed for percentage sperm motility, progressive motility and viability. Sperm concentration was also noted to ensure inseminates contained similar numbers of spermatozoa. Pooled semen was divided into four aliquots, three of which were transferred to a refrigerator $\left(4^{\circ} \mathrm{C}\right)$ for 24,48 or $72 \mathrm{~h}$. The remaining aliquot was placed on ice, designated as $0 \mathrm{~h}$ and used immediately for Al. At 24, 48 and 72 h, the assigned coldstored aliquots were used for AI. Six pens of four females were assigned to treatment groups as follows: one pen for each of the 24 and $48 \mathrm{~h}$ treatments and two pens each for the 48 and $72 \mathrm{~h}$ treatments. Females in each pen were inseminated with extended semen from the same treatment group, which avoided confusion in the event of a female 'parasitizing' the nests of other females (that is, one female laying eggs in the nest of another). Groups of females were inseminated twice a week with $100 \mu$ l extended semen. Eggs were incubated, assessed for fertilization and hatching success as described above.

\section{Experiment 4: impact of freezing and thawing methods on sperm motility and viability}

Pooled semen was subjected to three different freezing rates in three separate trials. Over the course of 3 weeks, ejaculates were collected weekly from eight males into catheters pre-filled with $100 \mu \mathrm{l}$ BPSE. After transfer to the laboratory and pooling, aliquots $(200 \mu \mathrm{l})$ were transferred to five microcentrifuge tubes $(1.8 \mathrm{ml}$; Perfector Scientific, Atascadero, CA). An equal volume of BPSE containing 8\% 
dimethylsulphoxide (DMSO), 2\% DMSO, 8\% glycerol, 2\% glycerol or no cryoprotectant $(\mathrm{v} / \mathrm{v}$; control) was added to yield final concentrations of 4 and $1 \%$ DMSO, 4 and $1 \%$ glycerol and $0 \%$ cryoprotectant, respectively. The osmolarity of the cryoprotectants was $1370 \mathrm{mOsm}$ (4\% DMSO), 460 mOsm (1\% DMSO), 1480 mOsm (4\% glycerol), $630 \mathrm{mOsm}$ ( $1 \%$ glycerol) and $280 \mathrm{mOsm}$ (control). Extended semen was mixed by inverting the microcentrifuge tubes three times before incubating at $4^{\circ} \mathrm{C}$ for a further $15 \mathrm{~min}$ (Gee and Sexton, 1990). The final concentration of extended semen was adjusted to approximately $1 \times 10^{9}$ sperm $\mathrm{ml}^{-1}$. Each sample was assessed for percentage sperm motility, progressive motility and viability to determine the effect of adding cryoprotectant. After loading and sealing $0.25 \mathrm{ml}$ French straws (TS Scientific, Perkasie, PA), spermatozoa were cryopreserved by (1) 'fast freeze', whereby straws were transferred to $2.5 \mathrm{~cm}$ above liquid nitrogen $\left(\mathrm{LN}_{2}\right)$ vapour and frozen at a rate of $60^{\circ} \mathrm{C}$ $\mathrm{min}^{-1}$ from $4^{\circ} \mathrm{C}$ to $-70^{\circ} \mathrm{C}$, before plunging into $\mathrm{LN}_{2} ;$; (2) 'slow-fast freeze', whereby straws were transferred to an ice-alcohol freezing unit (Biocool, FTS Systems Inc., Stone Ridge, NY) and cooled from $4^{\circ} \mathrm{C}$ to $-20^{\circ} \mathrm{C}$ at a rate of $1^{\circ} \mathrm{C}$ $\mathrm{min}^{-1}$, transferred to $2.5 \mathrm{~cm}$ above $\mathrm{LN}_{2}$ and cooled at approximately $60^{\circ} \mathrm{C} \mathrm{min}^{-1}$ to $-70^{\circ} \mathrm{C}$ before plunging into $\mathrm{LN}_{2}$ (Gee and Sexton, 1980); and (3) 'slow freeze', whereby straws were transferred to an ice-alcohol freezing unit and cooled at a rate of $1^{\circ} \mathrm{C} \mathrm{min}-1$ from $4^{\circ} \mathrm{C}$ to $-35^{\circ} \mathrm{C}$ before plunging into $\mathrm{LN}_{2}$ (Lake and Stewart, 1978). Freezing rates were determined by placing a thermistor probe (Fisher Scientific, Orlando, FL) inside a $0.25 \mathrm{ml}$ straw and reading the temperature at $15 \mathrm{~s}$ intervals. Straws were stored in $\mathrm{LN}_{2}$ for a minimum of $24 \mathrm{~h}$ before thawing using a 'fast' method (transferring to a water bath at $37^{\circ} \mathrm{C}$ for $30 \mathrm{~s}$ ) or a 'slow' method (transferring to an ice water bath at $4^{\circ} \mathrm{C}$ for $20 \mathrm{~min}$ ). After thawing, straw contents were released into a $1.8 \mathrm{ml}$ centrifuge tube, warmed to room temperature (approximately $24^{\circ} \mathrm{C}$ ) and assessed for percentage sperm motility, progressive motility and viability. Thawed motile spermatozoa were maintained overnight at $4^{\circ} \mathrm{C}$ and assessed for motility and status after $24 \mathrm{~h}$.

\section{Statistical analysis}

Data are presented as means \pm SEM. Differences between percentage sperm motility, progressive motility, percentage viability, percentage normal morphology and sperm concentration were examined by ANOVA, after testing the data for normality, using a multifactorial procedure and Fisher's least squares means post hoc test (Systat, 1989). Egg fertilization, embryo loss and hatching data were analysed using Student's $t$ test or Mann-Whitney $U$ test.

\section{Results}

\section{Ejaculate collection, semen and sperm traits}

During the first season, the efficacy of semen collection was recorded. A total of 180 ejaculates was collected from

Table 1. Mean ( \pm SEM) mid-season ejaculate and sperm traits for 20 representative Northern pintail ducks (Anas acuta)

Ejaculate volume $(\mu \mathrm{l})$

Semen $\mathrm{pH}$

Semen (undiluted) osmolarity (mOsm)

Sperm concentration $\left(\times 10^{9} \mathrm{ml}^{-1}\right)$

Sperm motility (\%)

Sperm progressive motility ${ }^{a}$

Structurally normal spermatozoa (\%)

Structurally abnormal spermatozoa (\%)

Head encased in cytoplasmic droplet

Microcephalic

Giant cell

Bent flagellum
Bent head/midpiece

$$
\begin{aligned}
66.0 & \pm 14.1 \\
8.5 & \pm 0.1 \\
275 & \pm 8.2 \\
5.7 & \pm 4.3 \\
57.4 & \pm 6.1 \\
2.7 & \pm 0.2 \\
85.6 & \pm 1.7 \\
7.1 & \pm 1.1 \\
3.3 & \pm 0.7 \\
3.2 & \pm 0.7 \\
0.5 & \pm 0.2 \\
0.2 & \pm 0.2
\end{aligned}
$$

${ }^{\mathrm{a}}$ On a scale of $0-5$, with 0 indicating no forward progression and 5 indicating rapid, linear movement.

46 drakes, and $84 \%$ of these were collected within $20 \mathrm{~s}$. Semen and sperm traits for the Northern pintail during the mid-breeding season are shown (Table 1; 20 typical ejaculates from 20 different drakes). Good quality semen was typically cream or white in appearance. In a parallel study that examined seminal traits throughout the breeding season (Penfold et al., in press), clear or opalescent semen contained large numbers of epithelial cells and only a few spermatozoa of poor motility and high abnormal morphology. Such ejaculates were typical of April and June, representing the onset and end of the season, respectively. Eleven (6.1\%) of the ejaculates contained significant amounts of accessory fluids resulting in low sperm concentrations $\left(<1 \times 10^{9} \mathrm{ml}^{-1}\right)$ and eight $(4.0 \%)$ samples were contaminated with faeces. These 19 ejaculates were not included in the studies. The mean semen volume, $\mathrm{pH}$ and osmolarity of ejaculates are shown (Table 1). Only about $15 \%$ of collected spermatozoa were pleiomorphic, with predominant abnormalities including a bent mid-piece, head encasement in a cytoplasmic droplet and microcephaly (Table 1).

Experiment 1: semen characteristics and sperm motility after ejaculate collection with and without BPSE at $24^{\circ} \mathrm{C}$ or at $4^{\circ} \mathrm{C}$

There was a significant advantage of diluting freshly collected spermatozoa 1:1 in BPSE on sperm motility and progressive status regardless of temperature $\left(24^{\circ} \mathrm{C}\right.$ versus $4^{\circ} \mathrm{C}$; Table 2). However, further dilution in BPSE $(1: 10$ or 1:100) caused a transient increase and a rapid decrease in progressive motility (data not shown). None of the treatments influenced the proportions of morphologically normal spermatozoa $(P>0.05)$.

Experiment 2: fertility and hatchability of eggs after artificial insemination with extended semen versus natural mating

Seasonal commencement of oviposition greatly en- 
Table 2. Effect of collecting Northern pintail (Anas acuta) ejaculate with or without Beltsville poultry sexton extender (BPSE) at ambient temperature or $4^{\circ} \mathrm{C}($ mean $\pm \mathrm{SEM})$

\begin{tabular}{lcccc}
\hline Treatment & Number of ejaculates & Sperm motility $(\%)$ & Sperm progressive motility* & Normal sperm morphology $(\%)$ \\
\hline Raw & 20 & $56.5 \pm 6.4^{\mathrm{a}}$ & $2.7 \pm 0.2^{\mathrm{a}}$ & $69.5 \pm 4.9^{\mathrm{a}}$ \\
$\mathrm{BPSE} 24^{\circ} \mathrm{C}$ & 20 & $72.0 \pm 4.1^{\mathrm{b}}$ & $3.6 \pm 0.1^{\mathrm{b}}$ & $75.3 \pm 3.8^{\mathrm{a}}$ \\
BPSE $4^{\circ} \mathrm{C}$ & 20 & $79.3 \pm 4.0^{\mathrm{b}}$ & $3.7 \pm 0.1^{\mathrm{b}}$ & $72.7 \pm 2.9^{\mathrm{a}}$ \\
\hline
\end{tabular}

*On a scale of $0-5$, with 0 indicating no forward progression and 5 indicating rapid, linear movement.

${ }^{a b}$ Column means with different superscripts differ significantly $(P<0.05)$.

hanced introduction of the Al catheter into the female tract. Insemination with $100 \mu \mathrm{l}$ of extended semen containing $0.31 \times 10^{9}$ motile spermatozoa (number of spermatozoa in $100 \mu \mathrm{l} \times$ percentage motility) resulted in fertilization and hatch rates equivalent to those after a natural mating (Table 3). In contrast, an Al dose of $200 \mu \mathrm{l}$ $\left(0.62 \times 10^{9}\right)$ decreased egg fertilization by $40 \%$ and hatchability by $>50 \%$ (Table 3 ). With the exception of the total number of motile spermatozoa inseminated, all other sperm parameters were similar (Table 3). When data were examined across individual birds, it was discovered that a single insemination $(100 \mu \mathrm{l})$ of $0.31 \pm 0.1 \times 10^{9}$ motile spermatozoa was sufficient to fertilize up to four eggs.

Experiment 3: fertility and hatchability of eggs after artificial insemination with $100 \mu$ l of extended coldstored semen

Cold storage through $72 \mathrm{~h}$ had no impact on normal sperm morphology or viability (Table 4). Sperm motility and progressive motility were unaffected through $48 \mathrm{~h}$, but decreased after $72 \mathrm{~h}(P<0.05$; Table 4$)$. Sperm concentration did not decrease over time and was similar $(P>0.05)$ for the four time storage groups (Table 5). However, hens in the $72 \mathrm{~h}$ group received lower total numbers of motile spermatozoa $\left(0.11 \times 10^{9}\right)$ than hens in the $0\left(0.14 \times 10^{9}\right)$, $24\left(0.15 \times 10^{9}\right)$ or $48 \mathrm{~h}\left(0.14 \times 10^{9}\right)$ groups owing to the decrease in sperm motility (Table 4). Nonetheless, live offspring were produced from eggs fertilized with extended semen cold-stored for up to $72 \mathrm{~h}$ (Table 5). The incidence of fertilization using spermatozoa stored for $72 \mathrm{~h}$ was only half that of the 0 and $24 \mathrm{~h}$ groups. One hen in the $0 \mathrm{~h}$ group failed to produce fertile eggs compared with two hens in the $24 \mathrm{~h}$ and $48 \mathrm{~h}$ groups each and seven hens in the $72 \mathrm{~h}$ group. Among birds within the groups, fertilization success ranged from 0 to $100 \%, 0$ to $90 \%, 0$ to $87.5 \%$ and 0 to $75 \%$ for the $0,24,48$ and $72 \mathrm{~h}$ groups, respectively. However, owing to individual variation among birds, there were no differences $(P>0.05)$ in fertilization success among the four time storage groups. Neither was there an effect $(P>0.05)$ of storage interval on incident of embryo loss or subsequent hatching success (Table 5).

\section{Experiment 4: impact of freezing and thawing methods on sperm motility and viability}

For all assessments, the number of viable (plasma mem- brane-intact) spermatozoa was equivalent to the number of motile spermatozoa. Only motility data are presented (Table 6). Cryopreserving duck spermatozoa in the absence of cryoprotectant caused complete (100\%) loss of motility and viability (Table 6). Concentrations of $1 \%$ DMSO and $1 \%$ glycerol were also ineffective in maintaining post-thaw motility and viability, with $0 \%$ of spermatozoa surviving the freeze-thaw process. Adding DMSO or glycerol $(4 \%)$ had a variable effect, reducing $(P<0.05)$ pre-freeze motility in two of three trials compared with controls (no cryoprotectant; Table 6). The highest numbers $(P<0.05)$ of motile and viable spermatozoa were recovered after the slow-fast freezing and slow thawing with either $4 \%$ DMSO $(32 \pm 8.3 \%$ ) or $4 \%$ glycerol $(35 \pm 0.0 \%$; Table 6). Slow thawing consistently resulted in higher $(P<0.05)$ numbers of motile spermatozoa after the fast and slow-fast freezing methods, but not $(P>0.05)$ after the slow freezing method. The number of spermatozoa retaining motility or viability $24 \mathrm{~h}$ after thawing was low (0-10\%), precluding Al trials.

\section{Discussion}

The present study describes normative ejaculate traits and the sensitivity of duck spermatozoa to cold storage, cryoprotectant concentration and freeze-thaw methods. There were five primary findings: (1) excellent quality ejaculates containing high proportions of motile and viable spermatozoa could be collected consistently from individual drakes within 20 s by simple massage; (2) duck sperm motility was enhanced after semen collection directly into BPSE, but was unaffected by short-term transfer to the laboratory at 24 versus $4^{\circ} \mathrm{C}$; (3) fertility after $\mathrm{Al}$ with extended fresh semen was similar to that of natural mating; (4) live offspring could be produced after Al with extended semen that had been cold-stored for up to $72 \mathrm{~h}$; and (5) sperm survival after cryopreservation was cryoprotectantand freeze-thaw rate-dependent. The use of $4 \%$ DMSO or glycerol combined with cooling at $1^{\circ} \mathrm{C} \mathrm{min}^{-1}$ to $-20^{\circ} \mathrm{C}$ and then $60^{\circ} \mathrm{C} \mathrm{min}^{-1}$ to $-70^{\circ} \mathrm{C}$ before $\mathrm{LN}_{2}$ immersion resulted in $35 \%$ post-thaw sperm motility. However, post-thaw motility was short-lived.

Obtaining a clean ejaculate is essential for securing viable spermatozoa that can withstand storage while retaining fertilizing capacity. Watery fluid or faecal contamination 
Table 3. Mean ( \pm SEM) fertilization and hatch success of Northern pintail (Anas acuta) eggs after natural mating or artificial insemination with 100 or $200 \mu \mathrm{l}$ freshly collected, cooled $\left(4^{\circ} \mathrm{C}\right)$ and extended semen

\begin{tabular}{|c|c|c|c|c|c|}
\hline $\begin{array}{l}\text { Insemination } \\
\text { method }\end{array}$ & $\begin{array}{l}\text { Number of } \\
\text { eggs }\end{array}$ & $\begin{array}{l}\text { Sperm concentration } \\
\qquad\left(\times 10^{9} \mathrm{ml}^{-1}\right)\end{array}$ & $\begin{array}{c}\text { Sperm motility } \\
(\%)\end{array}$ & $\begin{array}{c}\text { Fertilized eggs } \\
(\%)\end{array}$ & $\begin{array}{c}\text { Hatched eggs } \\
(\%)\end{array}$ \\
\hline Natural mating & 14 & $\mathrm{n} / \mathrm{a}$ & $\mathrm{n} / \mathrm{a}$ & $100 \pm 0.0^{\mathrm{a}}$ & $100 \pm 0.0^{\mathrm{a}}$ \\
\hline $\mathrm{Al}(100 \mu \mathrm{I})$ & 14 & $3.7 \pm 1.1$ & $84.4 \pm 4.4$ & $100 \pm 0.0^{\mathrm{a}}$ & $100 \pm 0.0^{\mathrm{a}}$ \\
\hline $\mathrm{Al}(200 \mu \mathrm{l})$ & 67 & $3.7 \pm 1.1$ & $84.4 \pm 4.4$ & $60.6 \pm 10.0^{b}$ & $47.6 \pm 10.0^{b}$ \\
\hline
\end{tabular}

${ }^{\mathrm{ab} C o l u m n}$ means with different superscripts differ significantly $(P<0.05)$.

Table 4. Northern pintail (Anas acuta) sperm traits after cold storage $\left(4^{\circ} \mathrm{C}\right)$ over time

\begin{tabular}{lcccc}
\hline Time $(\mathrm{h})$ & Sperm motility $(\%)$ & Sperm progressive motility* & Normal sperm morphology $(\%)$ & Sperm viability $(\%)$ \\
\hline 0 & $83.1 \pm 2.3^{\mathrm{a}}$ & $3.8 \pm 0.2^{\mathrm{a}}$ & $92.2 \pm 0.7^{\mathrm{a}}$ & $77.6 \pm 5.2^{\mathrm{a}}$ \\
24 & $80.4 \pm 2.4^{\mathrm{a}}$ & $3.7 \pm 0.2^{\mathrm{a}}$ & $90.2 \pm 1.0^{\mathrm{a}}$ & $79.0 \pm 5.9^{\mathrm{a}}$ \\
48 & $70.0 \pm 3.3^{\mathrm{a}}$ & $3.2 \pm 0.2^{\mathrm{a}}$ & $89.9 \pm 0.8^{\mathrm{a}}$ & $76.1 \pm 4.6^{\mathrm{a}}$ \\
72 & $63.9 \pm 4.0^{\mathrm{b}}$ & $2.9 \pm 0.2^{\mathrm{b}}$ & $89.3 \pm 0.7^{\mathrm{a}}$ & $76.7 \pm 4.4^{\mathrm{a}}$ \\
\hline
\end{tabular}

*On a scale of $0-5$, with 0 indicating no forward progression and 5 indicating rapid, linear movement.

${ }^{a b}$ Column means with different superscripts differ significantly $(P<0.05)$.

Table 5. Mean ( \pm SEM) fertilization and hatch success of Northern pintail (Anas acuta) eggs after artificial insemination with $100 \mu$ l of extended semen cold stored $\left(4^{\circ} \mathrm{C}\right)$ for $0,24,48$ or $72 \mathrm{~h}$

\begin{tabular}{lccccc}
\hline Storage time $(\mathrm{h})$ & Number of eggs & $\begin{array}{c}\text { Sperm concentration } \\
\left(\times 10^{9} \mathrm{ml}^{-1}\right)\end{array}$ & Fertilized eggs $(\%)$ & Embryo loss $(\%)$ & Hatched eggs $(\%)$ \\
\hline 0 & 50 & $1.7 \pm 0.3$ & $51.6 \pm 19.9$ & $9.8 \pm 7.3$ & $38.0 \pm 18.3$ \\
24 & 40 & $1.9 \pm 0.2$ & $51.5 \pm 16.5$ & $21.0 \pm 13.9$ & $30.5 \pm 12.3$ \\
48 & 56 & $2.0 \pm 0.2$ & $41.1 \pm 10.9$ & $1.3 \pm 1.3$ & $35.9 \pm 10.6$ \\
72 & 67 & $1.7 \pm 0.2$ & $22.3 \pm 7.6$ & $2.8 \pm 1.5$ & $19.5 \pm 2.8$ \\
\hline
\end{tabular}

There were no significant differences.

markedly reduce sperm longevity and fertilizing capacity in birds (Lake, 1971; Fujihara and Nishiyama, 1976). Excellent quality, uncontaminated ejaculates were collected routinely by a simple massage method. This has not been the case in other species such as the Muscovy duck (Cairina moshata) in which semen collection requires electroejaculation or an artificial vagina-intercept method (Tan, 1980; Watanabe et al., 1981; Maeda et al., 1984). Spermatozoa also have been collected by massage and by electroejaculation from the Pekin duck (Chelmonska et al., 1962; Pingel, 1972).

Waterfowl have a well-developed, spirally twisted copulatory organ, usually coiled within the ventral cloacal cavity. During mating, this organ uncoils to carry semen along numerous small crevices, presumably ensuring semen distribution within the female tract. Eversion of the copulatory organ during semen collection should be avoided to prevent the viscous semen spreading over the irregular surface and into the small crevices, impairing semen recovery.
Northern pintail drakes produced a wide range of semen volumes $(10-550 \mu \mathrm{l})$, similar to that of the domestic goose (10-600 $\mu \mathrm{l}$; Johnson, 1954), but averaging $66 \mu \mathrm{l}$, which was less than the mean $(390 \mu \mathrm{l})$ in Muscovy duck ejaculates (Tan, 1980). Northern pintail sperm concentration $\left(5.7 \times 10^{9}\right)$ was higher than that reported for the mallard $\left(1.3 \times 10^{9}\right.$; Stunden et al., 1998) and less than that of the Muscovy duck $\left(9.5 \times 10^{9}\right.$; Tan, 1980). Semen from most avian species has a near neutral $\mathrm{pH}$ (Pekin duck, 7.3; mallard duck, 6.8; domestic fowl, 7.0-7.3; Gee, 1983). Of the avian species studied to date, the Northern pintail appears to have the most basic semen of $\mathrm{pH} 8.5$, slightly higher than that of the whooping crane (Grus americana; $\mathrm{pH}$ 8.0).

The general morphology of individual Northern pintail spermatozoa was consistent with observations made in other Anseriformes (McFarlane, 1962). The Northern pintail ejaculate contained low percentages of abnormal spermatozoa, including those types already described in other avian species (bent mid-piece, swollen head, giant sperm and head encased in a cytoplasmic droplet; Gee, 
Table 6. Influence of sperm freezing and thawing method and cryoprotectant on Northern pintail

(Anas acuta) sperm motility

\begin{tabular}{|c|c|c|c|c|}
\hline Freezing method & Thawing method & Control $(0 \%)$ & Dimethylsulphoxide (4\%) & Glycerol (4\%) \\
\hline \multirow[t]{3}{*}{ Fast } & Prefreeze & $55 \pm 2.9^{\mathrm{a}}$ & $58 \pm 8.3^{\mathrm{a}}$ & $53 \pm 4.4^{\mathrm{a}}$ \\
\hline & Fast & $0 \pm 0.0^{b}$ & $4 \pm 1.3^{b}$ & $5 \pm 0.0^{b}$ \\
\hline & Slow & $0 \pm 0.0^{b}$ & $20 \pm 10^{c}$ & $22 \pm 6.7^{c}$ \\
\hline \multirow[t]{3}{*}{ Slow-fast } & Prefreeze & $73 \pm 4.4^{b}$ & $58 \pm 1.7^{a}$ & $62 \pm 3.3^{\mathrm{a}}$ \\
\hline & Fast & $0 \pm 0.0^{d}$ & $15 \pm 12^{\mathrm{c}}$ & $7 \pm 6.3^{c}$ \\
\hline & Slow & $0 \pm 0.0^{d}$ & $32 \pm 8.3^{\mathrm{e}}$ & $35 \pm 0.0^{\mathrm{e}}$ \\
\hline \multirow[t]{3}{*}{ Slow } & Prefreeze & $63 \pm 12^{b}$ & $43 \pm 7.5^{a}$ & $58 \pm 7.5^{\mathrm{ab}}$ \\
\hline & Fast & $0 \pm 0.0^{c}$ & $1 \pm 0.0^{c}$ & $1 \pm 0.5^{c}$ \\
\hline & Slow & $0 \pm 0.0^{\mathrm{c}}$ & $3 \pm 2.0^{c}$ & $2 \pm 1.0^{c}$ \\
\hline
\end{tabular}

abcde Column and row means within freezing method with different superscripts differ significantly $(P<0.05)$.

1983), as well as microcephaly. In a parallel study that examined sperm quality throughout the breeding season (Penfold et al., in press) the head encased in a cytoplasmic droplet malformation was found to be most prevalent near the end of the season. The bent midpiece defect was characterized by acute flexion in the midpiece region so that the head was parallel to the flagellum. This common defect occurs in diluted and stored chicken and turkey spermatozoa, probably as a result of osmotic stress (Bakst and Sexton, 1979; Bakst, 1990). The fowl spermatozoa plasma membrane in this region is known to be acutely susceptible to stress (Yamane et al., 1966). In the present study, it was likely that the bent midpiece in $>7 \%$ of the spermatozoa was not osmotically induced by adding BPSE because the osmolarity was adjusted to that of the neat ejaculate. Furthermore, BPSE extension did not increase the proportion of abnormal spermatozoa compared with the neat ejaculate.

Short-term (24 h) cold-storage of spermatozoa has been reported for domestic fowl spermatozoa, with a fertility success of $72 \%$ (versus $90 \%$ for fresh spermatozoa; Blesbois and de Reviers, 1992). Similarly, Al using shortterm $(24 \mathrm{~h})$ cold-stored turkey semen resulted in a fertility rate of $61 \%$ (versus $91 \%$ for unstored controls; Sexton, 1980a). Although Northern pintail sperm motility decreased after $72 \mathrm{~h}$, no change was apparent in other sperm traits. This finding was in contrast to another study of domestic drake semen (Kasai et al., 1996) that showed a 33\% decrease in viability after $24 \mathrm{~h}$ cold storage, assessed using the same staining combination used in this study. In the study of Kasai et al. (1986), semen was diluted 1:5 in Lake's diluent before storage (compared with 1:3 in BPSE in the present study) so a dilution effect (Mann, 1964) may have been partially responsible for this different result. In the present study, sperm concentration did not decrease through $72 \mathrm{~h}$ of storage. This is significant because avian sperm death often is accompanied by cell lysis and complete cell disintegration; for example, the rate of turkey sperm lysis can range from 17 to $33 \%$ of the unstored controls (Sexton, 1988b). Accordingly, as dead spermatozoa disintegrate in the ejaculate, the percentage sperm motility and viability may appear to remain unchanged over time.

Al with extended fresh semen achieved fertility and hatch success similar to those of natural breeding under captive conditions (100\%). Hatch success in wild Northern pintails is reported to be $32-68 \%$ (del Hoyo et al., 1992) owing to nest predation or abandonment. Thus, these results illustrate the potential of $\mathrm{Al}$ for improving overall reproductive efficiency in waterfowl species. Although copulation frequency during natural breeding remains unknown for the Northern pintail, the results revealed that insemination of $0.31 \times 10^{9}$ (motile) spermatozoa (Expt 2) was sufficient to fertilize at least four consecutively laid eggs. The lower fertilization success in Expt 3 compared with Expt 2 was probably related to inseminating numbers of spermatozoa below that required to achieve maximal fertilization. It is known that the sperm storage crypts of hens need to be adequately filled for optimal fertilization success (Brillard, 1993). As the $200 \mu \mathrm{l}$ $\left(0.63 \times 10^{9}\right.$ spermatozoa $)$ inseminations in Expt 2 failed to result in maximal fertilization, the optimal $\mathrm{Al}$ dose for the Northern pintail appears to be about $0.31 \times 10^{9}$ motile spermatozoa but over-insemination can be detrimental to fertility. The smaller number of spermatozoa inseminated in Expt 3 compared with Expt 2 at $0 \mathrm{~h}$ may account for the difference in fertilization success between the two experiments. In addition, the high degree of variability among females in Expt 3 made it difficult to demonstrate the loss of fertility in the cold-stored semen. Although there was no statistical effect through $72 \mathrm{~h}$ of storage on fertilization and hatch success, the range of fertilized eggs in the treatments groups $(0-100 \%, 0-90 \%, 0-87.5 \%$ and $0-75 \%$ for the 0 , 24, 48 and $72 \mathrm{~h}$ groups, respectively) indicated a trend in 
fertility reduction that was probably masked by suboptimal insemination doses.

Although Northern pintail spermatozoa are remarkably tolerant to cold storage at $4^{\circ} \mathrm{C}$, they were susceptible to the stresses associated with cryopreservation and thawing. Comparative assessments revealed that a combination of initial slow cooling followed by fast cooling (from 4 to $-20^{\circ} \mathrm{C}$ at a rate of $1^{\circ} \mathrm{C} \mathrm{min}^{-1}$, approximately $60^{\circ} \mathrm{C} \mathrm{min}-1$ to $-70^{\circ} \mathrm{C}$, immersed in $\mathrm{LN}_{2}$; Gee and Sexton, 1980) was most effective for recovering motile, viable spermatozoa. DMSO and glycerol were equally effective in protecting spermatozoa during freezing and thawing, but only at the $4 \%$ concentration. A $1 \%$ concentration of either cryoprotectant clearly was ineffective. A similar comparative approach for the sandhill crane and domestic fowl has revealed that $4 \%$ DMSO is the most effective cryoprotectant for preserving post-thaw sperm motility (Sexton and Gee, 1978). A standard cryoprotectant for poultry, DMSO also has the advantage of being safe when inseminated into females (Sexton, 1980b; Lake and Ravie, 1984). In contrast, glycerol has a contraceptive effect when used in a similar way (Lake and Stewart, 1978; Lake et al., 1980) and so must be diluted from the spermatozoa before $\mathrm{Al}$ (Lake et al., 1980). Northern pintail spermatozoa tolerated cryopreservation rates of approximately $60^{\circ} \mathrm{C} \mathrm{min}-1$, even though avian sperm generally must be cooled slowly (at approximately $1{ }^{\circ} \mathrm{C} \mathrm{min}^{-1}$; Sexton and Gee, 1978; Gee, 1983). Freezing in $\mathrm{LN}_{2}$ vapour has been reported for Muscovy spermatozoa by Watanabe et al. (1981), but no freezing rate was described. The $\mathrm{LN}_{2}$ technique requires further exploration because its simplicity could permit use under field conditions. Because sperm motility was not sustained beyond $24 \mathrm{~h}$ of thawing, it was not possible to determine the fertility of thawed spermatozoa in this experiment and more research is required to develop effective cryopreservation of Northern pintail duck spermatozoa. Lastly, and unsurprisingly, preliminary results (data not shown) indicated that post-thaw sperm viability is linked with pre-freeze sperm quality, and that good quality ejaculates resulted in more spermatozoa surviving the freeze-thaw process.

These studies provide a foundation for the collection and short-term storage of semen from waterfowl species. Although the cryopreservation of non-domestic waterfowl spermatozoa requires more work, cold storage $\left(4^{\circ} \mathrm{C}\right)$ of waterfowl semen appears to be a suitable alternative in the interim, providing adequate fertility for up to 3 days after collection. This time frame is sufficient to allow national and international shipment of semen from valuable waterfowl for conservation or commercial purposes.

This work was supported by the Philip Reed Foundation and Friends of the National Zoo. The authors are grateful to George Gee, Steve Leathery and Denise Holsberger for helpful advice on semen collection and $\mathrm{Al}$, the CRC Bird Unit for care and assistance and Francisco Palmer and Tanya Herzog for excellent technical assistance.

\section{References}

Ankney CD, Dennis DG, Wishard LN and Seeb JE (1986) Low genetic variation between black ducks and mallards Auk 103 701-709

Bakst MR (1990) Preservation of avian cells. In Poultry Breeding and Genetics pp 91-108 Ed. RD Crawford. Elsevier Science Publishers, Amsterdam

Bakst MR and Sexton TS (1979) Fertilizing capacity and ultrastructure of fowl and turkey spermatozoa before and after freezing Journal of Reproduction and Fertility 60 121-127

Blesbois E and de Reviers M (1992) Effect of different fractions of seminal plasma on the fertilizing ability of fowl spermatozoa stored in vitro. Journal of Reproduction and Fertility 95 263-268

Brillard JP (1993) Sperm storage and transport following natural mating and artificial insemination Poultry Science 72 923-928

Burrows WH and Quinn JP (1939) Artificial insemination of chickens and turkeys US Department of Agriculture Circular $\mathbf{5 2 5} 12$

Chelmonska B, Galuska H and Lisiecki J (1962) Electroejaculation in drakes Medycyna weterynaryjna 18 712-714

del Hoyo J, Elliott A and Sargatal J (1992) Anseriformes. In Handbook of the Birds of the World Vol. 1 p. 555 Eds J del Hoyo, A Elliott and J Sargatal. Lynx Edicions, Barcelona

Ellis-Joseph S, Hewston N and Green A (1992) In Global Waterfowl Conservation Assessment Management Plan p 2. Captive Breeding Specialist Group, Apple Valley, MN

Fujihara N and Nishiyama $\mathrm{H}$ (1976) Studies on the accessory reproductive organs in the drake 5. Effects of the fluid from the ejaculatory groove region on the spermatozoa of the drake Poultry Science $\mathbf{5 5}$ 2415-2420

Garner DL, Johnson LA, Yue ST, Roth BL and Haughland RP (1994) Dual DNA staining assessment of bovine sperm viability using SYBR-14 and propidium iodide Journal of Andrology 15 620-629

Gee G (1983) Avian artificial insemination and semen preservation. In IFCB Symposium on Breeding Birds in Captivity pp 375-398 Eds AC Risser, Jr and FS Todd. International Foundation for the Conservation of Birds, North Hollywood, CA

Gee G and Sexton TJ (1980) Artificial insemination and semen preservation of nondomestic birds Proceedings American Association of Zoo Veterinarians pp 55-58

Gee G and Sexton TJ (1990) Cryogenic preservation of semen from the Aleutian Canada Goose (Branta canadensis leucopareia) Zoo Biology 9 $361-371$

Hediger H (1965) Environmental factors influencing the reproduction of zoo animals. In Sex and Behavior pp 319-354 Ed. FA Beach. John Wiley and Sons, New York

Howard J, Bush M and Wildt DE (1991) Teratospermia in domestic cats compromises penetration of zona-free hamster ova and cat zonae pellucidae Journal of Andrology 12 36-45

Johnson AS (1954) Artificial insemination and duration of fertility in geese Poultry Science 39 230-232

Kasai K, Izumo A and Nishimura K (1996) Evaluation of sperm viability in fresh and stored drake semen using dual fluorescent staining Proceedings of Satellite Symposium in the $8^{\text {th }}$ American Association of Avian Pathologists Kinki University, Wakayama, Japan, 21-22

Lake PE (1971) The male in reproduction. In Physiology and Biochemistry of the Domestic Fowl pp 1411-1447 Eds DJ Ball and BM Freeman. Academic Press, New York

Lake PE and Ravie O (1984) An exploration of cryoprotective compounds for fowl spermatozoa British Poultry Science 25 145-150

Lake PE and Stewart JM (1978) Preservation of fowl semen in liquid nitrogen, an improved method British Poultry Science 19 187-194

Lake PE, Buckland RB and Ravie O (1980) Effect of glycerol on the viability of fowl spermatozoa, implications for its use when freezing semen. Cryoletters 1 299-304

McFarlane RW (1962) The Taxonomic Significance of Avian Sperm MSc Thesis, University of Florida

Maeda T, Terada T and Tsutsumi Y (1984) Morphological observations on frozen and thawed Muscovy spermatozoa British Poultry Science $\mathbf{2 5}$ 409-413 
Mann T (1964) The Biochemistry of Semen and the Male Reproductive Tract John Wiley and Sons, New York

Nei M, Maruyama T and Chakraborty R (1975) The bottleneck effect and genetic variability in populations Evolution 29 1-10

Penfold LM, Wildt DE, Herzog TL, Lynch W, Ware, L, Derrickson SE and Monfort SL Seasonal patterns of LH and testosterone and semen quality in the Northern pintail (Anas acuta) (in press)

Pingel M (1972) A contribution to artificial insemination in duck breeding. Wissenschaftliche Zeitschrift der Humboldt Universitat zu Berlin Mathematische-Naturwissenschatliche Reihe 21 179-181

Polge C (1951) Functional survival of fowl spermatozoa after freezing at $-79^{\circ} \mathrm{C}$ Nature $33170-72$

Ralls K and Ballou JD (1986) Preface to the proceedings of the workshop on genetic management of captive populations Zoo Biology 5 81-86

Sexton TJ (1977) A new poultry semen extender 1. Effect of extension on the fertility of chicken semen Poultry Science 56 1443-1446

Sexton TJ (1980a) Recent advances in semen storage of the fowl and turkey Proceedings of The 9th International Congress of Animal Reproduction and Artificial Insemination (Madrid) 527-533

Sexton TJ (1980b) A new poultry semen extender 5. Relationship of diluent components to cytotoxic effects of dimethylsulphoxide on turkey spermatozoa Poultry Science 59 1142-1144

Sexton TJ (1981) Development of a commercial method for freezing turkey semen I. Effect of pre-freeze techniques on the fertility of processed unfrozen and frozen-thawed semen Poultry Science $\mathbf{6 0}$ 1567-1573

Sexton TJ (1988a) Research note: influence of damaged spermatozoa on the fertility of turkey semen stored for 24 hours at $5^{\circ} \mathrm{C}$ Poultry Science 67 1483-1485

Sexton TJ (1988b) Comparison of commercial diluents for holding turkey semen 24 hours at $5^{\circ} \mathrm{C}$ Poultry Science 67 131-134

Sexton TJ and Gee G (1978) A comparative study on the cryogenic preservation of semen from the sandhill crane and the domestic fowl Symposium of the Zoological Society of London 43 89-95

Stunden CE, Bluhm CK, Cheng KM and Rajamahendran R (1998) Plasma testosterone profiles, semen characteristics and artificial insemination in yearling and adult captive mallard ducks (Anas platyrhynchos) Poultry Science 77 882-887

Systat Inc. (1989) Systat for the Macintosh Version 5.2 Evanston, IL

Tai JJ, Su YM, Huang HH, Terada T and Watanabe M (1983) Studies on the cryopreservation of drake semen. New strategies for improving animal production for human welfare Proceedings of the 5th World Conference on Animal Production pp 183-184

Tan NS (1980) The frequency of collection and semen production in Muscovy ducks British Poultry Science 21 265-272

Thurston RJ (1995) Storage of poultry semen above freezing for twentyfour to forty-eight hours Proceedings of the 1st International Symposium on the Artificial Insemination of Poultry-International Symposium on the Artificial Insemination of Poultry pp 107-122 Eds MR Bakst and GJ Wishard. Poultry Science Association, Savoy, IL

Tselutin K, Narubina L, Mavrodina T and Tur B (1995) Cryopreservation of poultry semen British Poultry Science 36 805-811

US Fish and Wildlife Service (1999) Status of Ducks Office of Migratory Birds Annual Report

Watanabe M, Matsumoto Y, Takeshita N and Terada T (1981) Fertility of Muscovy semen frozen for about three years Journal of the Faculty of Applied Biological Science 20 81-85

Yamane JS, Tsukunaga S and Takahashi T (1966) 'Hiroshima' method of artificial insemination of the domestic fowl Journal of Faculty of Fish and Animal Husbandry 6 395-429

Received 19 April 2000.

Accepted 23 August 2000. 